\title{
PRE-EMPLOYMENT SCREENING \& MONITORING OF THE HEALTH OF FOREIGN WORKERS
}

\author{
Khairul Anuar A' and Nooriah $\mathbf{M S}^{2}$. \\ 'Department of Parasitology, Faculty of Medicine, University of Malaya, 50603, Kuala Lumpur, Malaysia. \\ ${ }^{2}$ Department of Social and Preventive Medicine, Faculty of Medicine, University of Malaya, 50603 Kuala Lumpur, Malaysia.
}

During the past decade Malaysia saw a rapid influx of foreign workers. The majority of foreign workers are from Indonesia (70\%) and Bangladesh $(24 \%)$ while a smaller proportion of foreign workers originate from the Philippines, Thailand, Myanmar, Sri Lanka, Pakistan and India (1). These foreign workers are employed to do menial jobs in the agricultural, domestic, manufacturing, service and construction industries. Over the years, the cumulative effect of this phenomenon has created an impact on the Malaysian economic, social and health sectors. Some of the problems related to foreign workers pertain to the detection of communicable diseases and their utilization of government health services.

In order to prevent the transmission of infectious diseases to the local population the Malaysian government, under the auspices of the Ministry of Health (MOH), has devised a mechanism to screen potential foreign workers to ensure that only those who are free from communicable diseases and serious illnesses are allowed to work in Malaysia (1).

In Malaysia the agency that is responsible for issuing work permits to foreign workers is the Immigration Department. The department will only issue the work permits after the foreign workers are certified medically fit. The Immigration Act (1959) empowers the relevant authorities to stop any immigrant who is infected with any communicable disease from entering Malaysia.

The Ministry of Health is responsible for the formulation and implementation of policies pertaining to the medical examination of foreign workers. The Ministry, with the cooperation of the relevant authorities in the workers' home countries, have identified and appointed the clinics or hospitals for pre-employment medical examination. The Malaysian government has made it mandatory that all potential foreign workers undergo a full medical examination at the designated health facilities in their home countries prior to their employment in Malaysia. The medical examination report issued by the doctors in the foreign workers' home country is valid for 3 months from the date of the examination and employers are encouraged to have their workers re-examined in Malaysia prior to or at the beginning of their employment. However, many employers are not aware of this matter, or they tend to overlook this is- sue. Hence the majority of the local employers tend to register their foreign workers for the medical examination nine months later when their workers' permits are due for renewal.

After being accepted for employment in Malaysia, all foreign workers have to undergo a medical examination annually. The medical report is required by the Immigration Department for renewal of the work permit. This medical examination is conducted approximately 3 months before the worker's work permit expires. For new arrivals it will be approximately 9 months after their entry into Malaysia.

Since $\left.\right|^{\text {st }}$ December 1997 all procedures related to the medical examination of foreign workers are being closely monitored and coordinated by a private agency, namely, FOMEMA (Foreign Workers Medical Examination Agency) (2). Prior to this date the medical examinations of foreign workers were not monitored and there were problems related to false documentations and certifications of medical reports.

FOMEMA has offices in the major towns in Peninsular Malaysia, Sabah and Sarawak. The FOMEMA headquarters in Kuala Lumpur maintains a central database of the medical reports of all legally registered foreign workers and the agency's computers are linked with the

Immigration Department and the $\mathrm{MOH}$. Annually about four to five hundred thousand foreign workers from Peninsular Malaysia register with FOMEMA for their medical examination to determine whether they can continue working in this country. In Peninsular Malaysia, the number of foreign workers that have been examined by doctors registered with FOMEMA between 1998 to 2001 are as follows:

\begin{tabular}{cc}
\hline Year & $\begin{array}{c}\text { Number of foreign } \\
\text { workers examined in } \\
\text { Peninsular Malaysia }\end{array}$ \\
\hline 1999 & 464,221 \\
2000 & 431,909 \\
2001 & 506,405 \\
\hline
\end{tabular}

Source: FOMEMA

Correpsondence:

Protessor Khainul Anuar Abudullah

Faculty of Medicine

University of Malaya, 50603 Kuala Lumpur:

Malaysia 
The above figures do not include the professional and managerial expatriate workers, illegal migrant workers and refugees (2). Officially there are 900,000 migrant workers employed in Peninsular Malaysia, Sabah and Sarawak but unofficially, it is estimated that there are one million foreign workers who are in the country illegally (3) and hence the latter group of foreign workers are not documented nor screened.

Annually, all registered foreign workers are subjected to a full physical examination and a chest $x$-ray. Samples of blood and urine are collected and sent to laboratories appointed and monitored by FOMEMA. The agency has drawn up guide lines, check lists and protocols for the participating general practitioners, laboratories and $\mathrm{X}$-ray centers. All foreign workers are screened to detect for the presence of tuberculosis, HIVIAIDS, syphilis, malaria, Hepatitis B, leprosy, pregnancy, drug abuse, cancer, epilepsy and psychiatric illness and if any of these conditions are present the worker will not be certified for employment. In such instances, the foreign worker will be considered "UNFIT" for employment and the Immigration Department will not renew the worker's permit (4).

All general practitioners and laboratories registered with FOMEMA are required to be online and to transmit the findings of the medical examinations and laboratory results to the latter agency. The medical reports are reviewed and are then electronically transmitted to the Immigration Department. Thus, when a foreign worker submits his application for renewal of his work permit, the Immigration Department will have the worker's medical report on the computer screen. The worker will be certified as either "FIT" or "UNFIT' for employment (4).

Since 1999, officials from FOMEMA and the $\mathrm{MOH}$ have also been conducting random checks on immigrant workers upon their arrival at Kuala Lumpur International Airport (KLIA). The incoming foreign workers' medical examination documents are reviewed and blood and urine samples are collected and examined to verify that the medical reports are authentic. Those workers with incomplete medical reports are subjected to a full medical examination. In 1999 a random sample of 5036 immigrant workers who were certified fit by the doctors in their home country were examined and 2. 3\% ( 115 cases) were found to be medically unfit for employment. Most of those who were found to be unfit were positive for Hepatitis B (76\%), syphilis (5\%), drugs $(10 \%)$ and HIV (1\%). Nine women $(8 \%)$ were found to be pregnant (4). Similar random checks are also currently being carried out at Penang airport, Port Klang, Malacca (Dumai) and Muar (4).

Between October $200 \mathrm{I}$ and January 2002, FOMEMA conducted a study on a sample of 4,929 workers which comprised only $1 \%$ of the total number of foreign workers $(427,954)$ examined by all the doctors registered with the agency during that period (5). The study population comprised $57 \%$ males and $44 \%$ females and the majority were in the age group 30 to 39 years. The foreign workers were mainly from Indonesia (70\%) and Bangladesh (22\%). They were mainly engaged in the manufacturing (32\%), domestic (31\%), agriculture (19\%), construction $(11 \%)$ and service $(7 \%)$ industries. Most of these foreign workers were located in Selangor, Johor and Wilayah Persekutuan.

The study showed that $1.6 \%$ (78) of the workers were found to be unfit for employment and they were mainly aged more than 39 years. They were also mainly employed in the agricultural sector. Hepatitis B, tuberculosis and sexually transmitted diseases were the main problems detected among those who were certified medically unfit for employment (5).

The current system of monitoring the health of foreign workers is only confined to those who are legally registered and working in the menial job categories. Professional and managerial expatriate workers and their accompanying family members, illegal migrant workers and refugees are not included in this system.

In view of the presence of large numbers of illegal migrant workers and a substantial number of refugees in Malaysia and the fact that they are marginalized from the mainstream, their health problems may pose a problem to the community in which they live. If they are harboring any communicable disease and do not seek treatment, they will be the reservoir for transmission of the disease to the community. Eventually, they will also be burdening the country's public curative and health services.

Currently, the potential foreign worker is required to have his medical examination at the appointed clinics in his home country. Unfortunately, the Malaysian $\mathrm{MOH}$ does not have any direct control with regards to the conduct of the medical examinations in the workers' home countries. Thus the system can be easily abused. This is reflected in the documented statistics of conditions such as HIV, syphilis, Hepatitis B, drugs and pregnancy among incoming potential foreign workers who were randomly re-examined by FOMEMA at the port of entry even though they were apparently certified as medically" "FIT" by the doctors in their home country. This observation shows that the current pre-employment medical examination and certification in the foreign workers' home country should be reviewed and any deficiencies in the system should be rectified.

There should also be a mechanism to monitor the health of the managerial and professional expatriate workers and their accompanying family members. It is evident 
that in the current system, the pre-employment medical examination in the workers home countries is likely to be open to abuse. There are no inbuilt quality control measures and the authenticity of the medical reports are questionable because random checks on foreign workers at the ports of entry have revealed results that contradict with the reports of the doctors who examined and certified them in their home countries.

\section{Acknowledgements}

We would like to acknowledge our gratitude to Dr. Jit Singh, Director of FOMEMA who provided the information about the organization and the statistics pertaining to the health problems of foreign workers.

\section{FOREIGN COUNTRY}

MALAYSIA

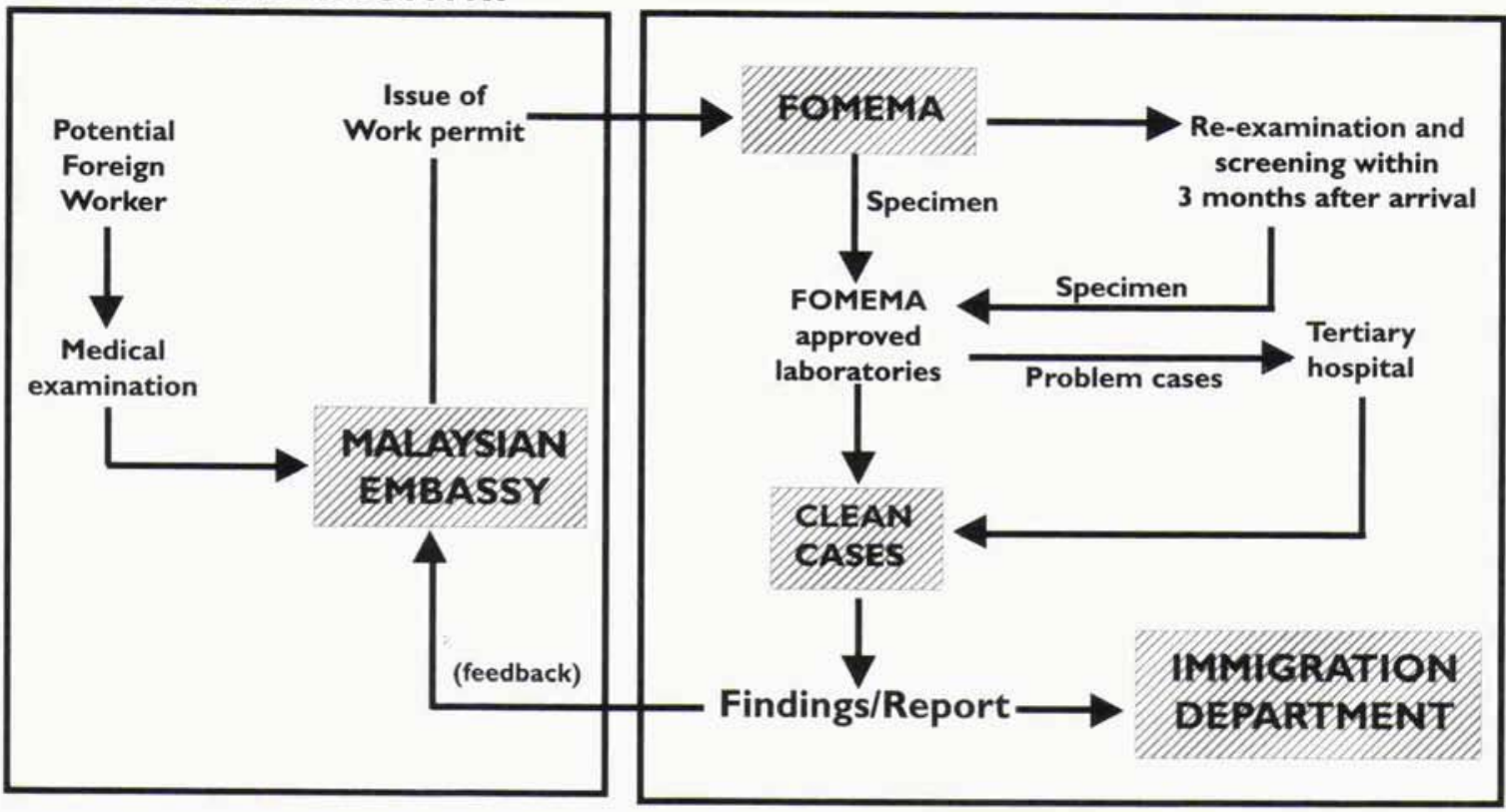

Figure I. Proposed scheme for foreign workers seeking employment

Thus it is proposed that all potential foreign workers who have cleared the pre-employment medical examination in their home countries. should be re-examined and screened (physical examination, blood examination and chest $X$-ray) within the first 3 months of their arrival. These examinations should be monitored by FOMEMA. All doubtful and problem cases should be referred to tertiary hospitals e.g UMMC (University Malaya Medical Centre), HUKM (Hospital University Kebangsaan Malaysia), USM (University Sains Malaysia) Kubang Kerian. (Figure I).

\section{References}

I. Monitoring the Health of Foreign Workers. Malaysia's Health 2000.Technical Report of the Director-General of Health, Malaysia. Ministry of Health Malaysia.

2 FOMEMA. Historical Background. Unpublished document.

3. A. Fernandez. The Philippine Migration Trail. Health Concerns of Filipino Migrant Workers in Malaysia. Internet Communication, May 15, 2002 at http:// www.ips.org/ migration/aegile.html

4. FOMEMA. Medical Examination System. Unpublished document.

5. FOMEMA, 2002. A Study on the Health Status of Foreign Workers in Peninsular Malaysia. Unpublished document. 